\title{
Revision procedure for stent extension in a sharply angulated gastroesophageal junction cancer using endoscopic countertraction
}

A 95-year-old man with locally advanced gastroesophageal junction cancer diagnosed 2 months previously was referred for consideration of stent revision due to recurrent dysphagia. The patient had undergone stent treatment before, complicated by failure to advance a conventional applicator system through the short but tight and sharply angulated malignant stricture. Therefore, on that occasion, a $60-\times 10-\mathrm{mm}$ uncovered gastroduodenal through-the-scope (TTS) stent was placed.

Recent endoscopy excluded stent migration, but the proximal stent end barely bridged the stricture and appeared partially tilted, giving rise to an almost $90^{\circ}$ angle to the esophageal axis, consistent with the clinical impression of poor stent function ( $\triangleright$ Fig.1a). A decision was therefore made to perform stent-in-stent revision to extend the stent, placing another stent into the more proximal part of the esophagus. To this end, a 35-inch stiff guidewire (Jagwire; Boston Scientific) was preinserted into the stomach after endoscopic passage through the stent, which thus excluded threading through the stent meshes. However, during advancement of the applicator system of the $100-\times 20-\mathrm{mm}$ partially covered self-expanding metal stent (SEMS; Taewong Medical), resistance was noted, with stent and guidewire deformation apparent on endoscopy and fluoroscopy ( Fig.1 b, - Fig.2a). As a novel endoscopic bailout for this rare situation, we utilized endoscopic countertraction after parallel reinsertion of the gastroscope by grasping the proximal stent ( $\mathbf{F i g . 1} \mathbf{c}$, - Fig. 2b). The scope with the grasped stent was kept under tension to straighten the stent and allow axial alignment. At the same time, the applicator system was cautiously advanced with initial judicious to-and-fro movements until resistance was no longer encountered ( $\triangleright$ Fig. 1 d, $\checkmark$ Fig. 2 c; Video 1). Finally, the proce-

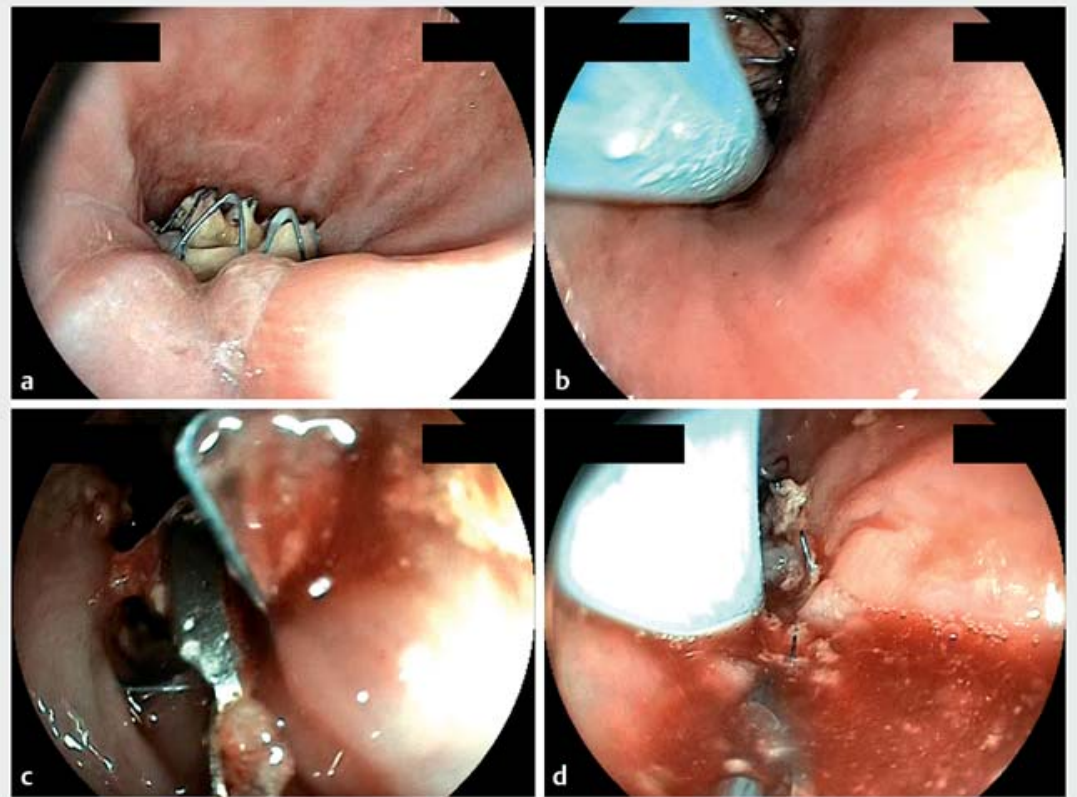

- Fig. 1 Endoscopic images. a Initial position with a partially tilted proximal stent end due to sharp angulation of the gastroesophageal junction cancer with poor clinical stent function. b Increasing stent deformation during attempts to advance the applicator system through the stent under wire guidance (the guidewire was placed endoscopically after passage into the stomach, thus excluding threading through stent meshes). c Endoscopy-guided grasping of proximal stent meshes with a forceps. $\mathbf{d}$ Successful advancement of the applicator system, followed by stent-in-stent deployment as per standard procedure after removal of the forceps.
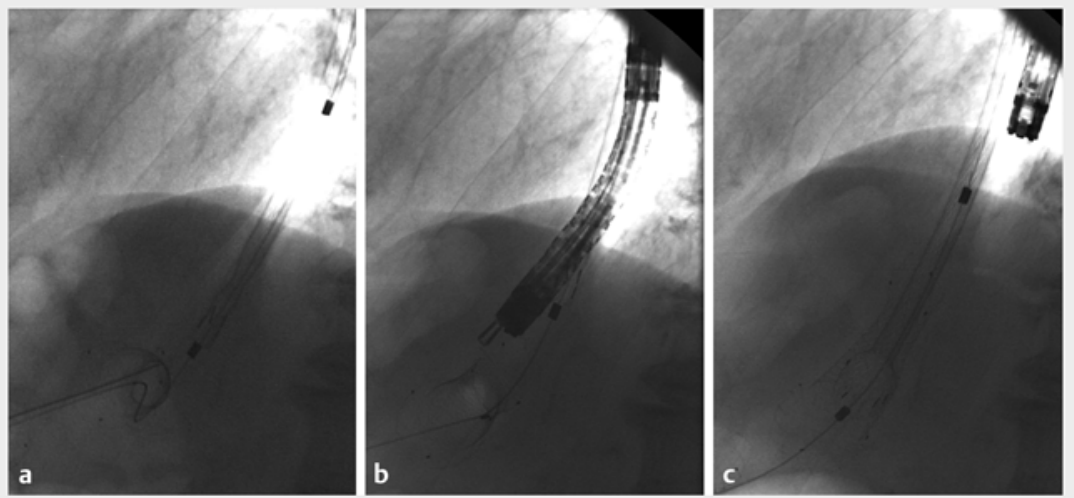

- Fig. 2 Fluoroscopic images. a Deformation of the in-situ stent and guidewire during conventional wire-guided advancement of the applicator system due to hooking into the stent meshes. $\mathbf{b}$ Endoscopic countertraction exerted by grasping the proximal end of the stent in order to straighten the stent and enable proper axial alignment. c Successful introduction and partial deployment of the stent-in-stent revision/extension. 


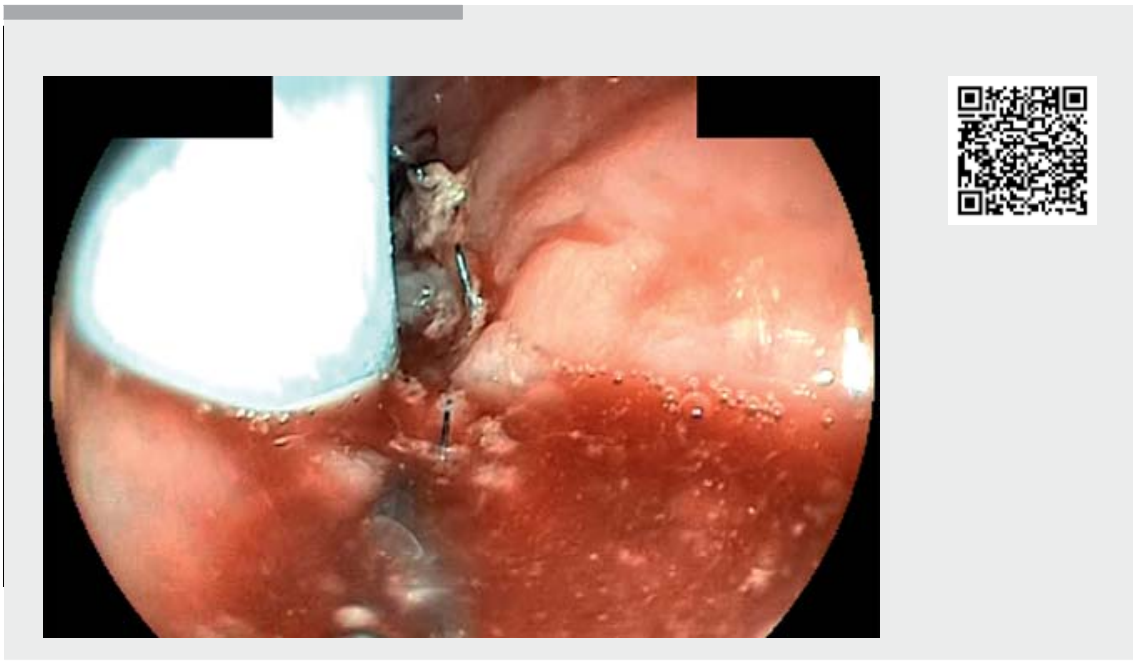

Video 1 Clinical utility of endoscopic countertraction to enable a tricky revision procedure for stent extension in a sharply angulated gastroesophageal junction cancer.

\section{References}

[1] Spaander MC, Baron TH, Siersema PD et al. Esophageal stenting for benign and malignant disease: European Society of Gastrointestinal Endoscopy (ESGE) Clinical Guideline. Endoscopy 2016; 48: 939-948

[2] Ramirez FC, Dennert B, Zierer ST et al. Esophageal self-expandable metallic stents - indications, practice, techniques, and complications: results of a national survey. Gastrointest Endosc 1997; 45: 360-364

[3] Hindy P, Hong J, Lam-Tsai Y et al. A comprehensive review of esophageal stents. Gastroenterol Hepatol (N Y) 2012; 8: 526-534

\section{Bibliography}

Endoscopy 2021; 53: E303-E304

DOI 10.1055/a-1270-6418

ISSN 0013-726X

published online 8.10 .2020

(c) 2020. Thieme. All rights reserved.

Georg Thieme Verlag KG, Rüdigerstraße 14, 70469 Stuttgart, Germany quate stent-in-stent extension achieved. Esophageal and/or gastroesophageal stenting is usually straightforward, with high reported technical success rates at primary and/or secondary deployment $[1,2]$. Notwithstanding, however, isolated tricky clinical situations may arise, and this novel approach utilizing endoscopic countertraction might be instrumental in overcoming such occasional challenges [3].

Endoscopy_UCTN_Code_TTT_1AO_2AZ

\section{Competing interests}

The authors declare that they have no conflict of interest.
The author

\section{Vincent Zimmer ${ }^{1,2}$}

1 Department of Medicine, Marienhausklinik St. Josef Kohlhof, Neunkirchen, Germany

2 Department of Medicine II, Saarland University Medical Center, Saarland University, Homburg, Germany

\section{Corresponding author}

\section{Vincent Zimmer, MD}

Department of Medicine, Marienhausklinik St. Josef Kohlhof, Klinikweg 1-5, 66539 Neunkirchen, Germany Fax: +49-6821-3632624 vincent.zimmer@gmx.de

\section{ENDOSCOPY E-VIDEOS}

https://eref.thieme.de/e-videos

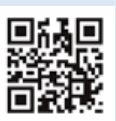

Endoscopy E-Videos is a free access online section, reporting on interesting cases and new

techniques in gastroenterological endoscopy. All papers include a high quality video and all contributions are freely accessible online.

This section has its own submission website at https://mc.manuscriptcentral.com/e-videos 